\title{
A Study on Profit System in Small and Medium Sized Enterprises
}

\author{
${ }^{1}$ Olexiy Bakhanov Bogdan \\ ${ }^{1}$ Sociology Department, Kyiv Polytechnic Institute, Ukraine, 03056 \\ 'bogdanolexity37@hotmail.com
}

\begin{abstract}
Article Info
Journal of Journal of Enterprise and Business Intelligence (http://anapub.co.ke/journals/jebi/jebi.html)

Doi: https://doi.org/10.53759/5181/JEBI202101007
\end{abstract}

Received 20 September 2020; Revised form 15 October 2020; Accepted 25 December 2020.

Available online 05 April 2021.

(C2021 Published by AnaPub Publications.

\begin{abstract}
Profit is the main objective upon which most economic units are based and the criterion on which companies depend on their survival and sustainability in the labor market, and there are many parties that depend on it in drawing up their policy to deal with them in light of the profits they achieve, such as owners, investors, creditors, and all users Internal and external according to the degree of interest of each user in the profits. Despite the importance of that element, there are many factors that affect the achievement of profits and their fluctuation from year to year, which requires identification and study of them, and the adaptation of accounting information systems in a manner that reduces their effects and their implications, for the purpose of assisting top management in making rational decisions on it. The research highlights those factors, and many conclusions and recommendations have been reached.
\end{abstract}

Keywords - Accounting Profits; Accounting Information; Fluctuation Factors; Volume of Sales; The Volume of Assets; Variable and Fixed Costs; Sale Price; A Mix of Products.

\section{INTRODUCTION}

That the continuity and survival of companies and their development and expansion is through the achievement of profits so profit is the main objective that companies and institutions seek to achieve through the departments and employees [3]. Profit is also a function for many users of financial statements such as current and prospective investors and other users. It is no secret that companies differ in their ability to generate profits as well as that these profits are affected by a set of factors that cast a shadow on the final result of the performance of the work of companies. In this study, we will attempt to identify these factors and their effect on accounting profits and analyze them to reach the reasons that lead to a change in the final profits of the accounting units [10]. The research contains four main topics, the first relates to the research methodology, and the second is the theoretical aspect includes the factors that affect the fluctuation of profits (sales, changes in product selling prices, changes in cost levels, the effects of the sales mix on income, and changes in income during periods of economic inflation, The impact of current assets on profitability, company management, and policies), the third for the practical side, and the fourth for the most important conclusions and recommendations [11], [16].

\section{RESEARCH METHODOLOGY}

\section{Research problem}

The basic function of an organization's efficiency is the extent to which it achieves profit. The strategic objective of companies goes beyond that (profit-making) function, how to maintain and sustain it, and even strive to develop it. Many factors are influencing that profit, but many companies neglect attention to those Factors, study and lay the foundations to avoid their negative effects, and here lies the problem of research, and by answering the questions below we are trying to find a solution to that problem [8].

- What are the factors that lead to fluctuations in corporate profits?

- How does the factors that cause fluctuates affect the level of profits? 


\section{Research importance}

The importance of research in dealing with one of the most important criteria for evaluating the performance of companies in the profit without which the company is unable to continue and growth on the one hand, and know the reasons and factors that prevent the profit or affect the level of preservation, on the other [9].

\section{Research Objective}

Aims mainly at achieving the following objectives:

- Identify factors that show changes and fluctuations in profits.

- Studying these factors and their relationship to profits and trying to find a formula to control them.

- Assisting the entity in increasing the accounting profits by supporting the factors that increase the continuous accounting profits and placing these factors at the disposal of the decision-makers in the accounting units [19].

\section{Research Hypothesis}

Research through the theoretical framework and applied study to test the following main hypothesis: (There is no statistically significant positive correlation between the group's core factors and the fluctuation of accounting profits).

\section{Research limits}

- The limits of spatial research: limited to SMEs industrial in the province of Basra, southern Iraq.

- Limits of time research: The period (2018-2019).

\section{Community and Research Sample}

The research community in the industrial sector has a large role in the growth of the Iraqi economy. The statistical society consists of thirty SMEs from the private sector of the companies registered in the Basra Chamber of Industry. The sample of the research was selected from this statistical society of 45 employees distributed among the company manager, accountant, and auditor Internal to each company.

\section{Research Method}

The research was based on a review of the theoretical concept of the factors influencing the accounting profits, their importance and the benefits of their knowledge, first on the group of Arab and foreign sources and references, and secondly, the preparation of the questionnaire and its analysis using a set of statistical methods, namely arithmetic mean standard deviation and T-test. Using the statistical package of social sciences (SPSS).

\section{THEORETICAL SIDE}

\section{Definition of SMEs and their characteristics}

The definitions and characteristics of small and medium enterprises vary from one country to another according to the difference in their capabilities and economic and social conditions, the degree of industrialization, the nature of the components and factors of industrial, commercial, agricultural, and service production, the quality of existing traditional craft industries such as modern industry, population density, the availability of human assets and the degree of qualification, Its skill and the general level of wages, income and other economic and social aspects that determine the features and nature of small enterprises in it, and then the definition varies according to the goal or purpose of it. Although there is no agreed international definition of medium and small enterprises, there is an agreement on the criteria by which the different sizes and levels of the facilities can be defined, among the most common criteria such as the number of employees, the size of the investment, the annual sales volume (annual business) and these differ according to the law every country. 


\section{Factors Affecting Accounting Profit Fluctuations}

\section{Accounting profit concept}

Before we examine the factors affecting the fluctuation of accounting profits, we should first identify the concept of accounting profit and the difference between it and the concept of profit among economists. "Profit is the maximum of economic resources that an individual can consume within a certain period, with his wealth at the end of that period as large as it was at the beginning. Economists, through this concept, maintain the real value of capital. "The method of capital preservation is particularly important in periods of economic inflation and the consequent sharp change in the monetary unit. The core characteristic of the economic analysis of income is the outlook, is a measurement that depends on expectations for the future [1], [12]. As for the accounting point of view, they neglect any change that occurs in the purchasing value of the scale by which the net assets of the enterprise are measured at the beginning and the end of the period and they adhere to the principle of historical cost in establishing the assets and liabilities of the establishment, they depend on the movement of activities that occur during the accounting period, which is called "Operations entrance" because it focuses on financial operations "revenues, expenses, gains and losses" that occur in the facility during the financial period, and the future flow in the facility can be predicted and the operations approach is based on a set of principles and rules that achieve a logical and coherent treatment of the events, operations and conditions related to the economic unit. This entry has great flexibility in disclosing the components of income for the period, which is appropriate for the multiple needs of users of the financial statements [17], [12].

\section{How to calculate the net accounting profit}

Accountants determine profit by growth in equity. This is called a budget equation or by matching revenue with costs or what is called an income statement. Net profit for the period = revenue - expenses + gains - losses to give a complete picture of the activities of the establishment during the financial period, these operations must be arranged according to a unified list to show these operations and the statement of net profit, and this is what we find in the income statement. Despite the necessity of determining the final number of the firm's net profit during each financial year, knowing the details of the items that make up the final net profit number is not less important than the profit number itself, and for this purpose, the income statement is prepared to show details of revenues and expenses during the period, and if the total increases Revenues are based on total expenses, so the result of the establishment's operations during the period will be net profit, and vice versa, the result will be a net loss for the period. The multi-step income statement is the best model for presenting information and operations at the end of the financial period, and this model is distinguished from others by providing more useful information for users of published financial statements, which gives it a great ability to apply the principle of disclosure, and it also distinguishes between the profit achieved from regular activities And between investment sources such as interest, rents, and others.

\section{Factors affecting the fluctuation of accounting profits}

After knowing the concept of accounting profits and how they are calculated, the most important factors that affect the fluctuation of accounting profits will be studied, but it is necessary before that to clarify what is meant by the fluctuation of accounting profits so that the vision is complete about the factors that lead to fluctuation of accounting profits is the change in results for the net accounting profits shown in the lists Final financial increase or decrease in comparison with its results shown in the previous financial years of the establishment and this change occurs in most commercial establishments over the successive financial years and each of them has different causes and factors that led to this change, and will The most important factors that have a direct effect on accounting profit results are taken.

\section{First: Sales (change in the level of sales activity or sales value)}

The importance of sales is evident in the fact that it is the main activity of commercial establishments, and it has the largest share in achieving and increasing profits. And it can be said that the net sales are the main revenue of the establishment's activity and the final profit value of the project depends on it, and sales are a process that the establishment undertakes to achieve profit by offering, marketing and promoting the commodity after preparing it for sale. Sales are associated with profit in a direct relationship with the assumption that other factors are constant from variable costs and unit selling price and others. Increasing sales volume in a specific period as it appears in the income statement leads to an increase in overall profit in the same period with the constant cost of sales, and for this, there is 
interest A lot of management on the course of the sale process and the increase in its quantities and finding the appropriate conditions to achieve the largest amount of sales in the financial period and gain consumer satisfaction about the goods provided by the facility. But how do sales directly affect income in a direct relationship? The value of sales is not considered profitable before it covers the total costs (fixed and variable) borne by the enterprise, and when the sales revenue reaches a certain level equal to the costs, the income at the equal point is equal to zero, and this is known as the break-even point. A break-even point is defined as that point or that level of production at which the total revenue is equal to the total costs and the profits are equal to zero and is used to find out the extent of the impact of different alternatives on operating income [21]. The break-even point can be reached in more than one way, including the equation method, as follows:

Sales revenue $=$ variable costs + fixed costs

By analyzing each element of the equation: Sales amount $\mathrm{x}$ sale price per unit $=$ [sales amount $\mathrm{x}$ variable cost per unit $]+$ fixed costs. And there is another method called the method of return (the contribution margin). This method depends on determining the return on the contribution per unit, which is the difference between the price per unit and its variable cost [7], [15]. And the return on the contribution of the unit means that amount in the contribution of the unit sold in covering the fixed costs and generating the profits for the period and therefore it is represented by the increase in the profits of the establishment or the decrease in its losses as a result of the increase in the volume of sales by one unit and the equation on which this method depends is: the amount of sales $=$ fixed costs $\backslash$ sale price of the unit - variable cost per unit.

After the amount of sales or sales revenue is equal to the total costs and covers them, each unit sold after that is an increase in profit (i.e. the return of its contribution represents a net profit of the enterprise), and it is possible through the previous two equations to determine the number of sales required to achieve a targeted profit that the establishment seeks to achieve.

The profit that is achieved from a certain amount of sales in a given period will increase or decrease as the amount of sales increases or decreases with the assumption that the selling price per unit of the product remains constant and the costs fixed and variable in the comparative years between them. And the relationship between profits and sales can be clarified through the study of the profitability of sales. The study of profitability of sales, or as it is sometimes called (the voluntary power of the enterprise), aims to know the facility's ability to generate profits through sales and is studied through the following ratios.

Profitability ratio of sales $=($ Net profit after tax $\backslash$ Net sales $) * 100 \%$

This ratio shows the ability of one dinar of sales to create (generate) profits, and the higher this percentage, the more a good indicator for the facility. Gross profit margin is calculated as follows: (Gross profit $\backslash$ Net sales)*100\% This ratio shows the ability of one dinar of sales to generate profits and their increase is considered a positive indicator, and this ratio is considered more indicative and better for performance evaluation, especially when compared with similar establishments because it reflects the result of the primary operational activity of the facility.

\section{Activity profit margin, this ratio is calculated as follows}

(Activity profit before interest and taxes $\backslash$ Net sales)*100\% And it shows the ability of one dinar of sales to create profits before deduction of interest and taxes and its rise is considered a positive indicator for the facility, and this ratio with the ratio of the edge of the gross profit is better to measure the facility's ability to face the difficult conditions that may appear to the facility, especially about changing sales volume Or change the prices of goods or change the costs of production, and it is normal that this ratio is in the middle position between the percentage of profitability of sales and the edge of the overall profit. And a summary of what has been presented about the concept of sales and its relationship with profit, we find that an increase in the volume of sales or the value of sales in a specific period from another previous period leads to maximizing profits and increasing them, and vice versa, and therefore the relationship is direct.

However, an increase in sales per se does not indicate an increase in profits because it may coincide with changes in other elements such as selling prices and costs, which determines the increase in profit. Management has a large and fundamental role in sales through marketing, supply, merchandising, studying markets and consumer tastes to determine the volume of production and the unit price in a way that suits the market to have the ability to maximize profits. 
Second: changes in the prices of selling products

Accounting profits are closely related to the selling price of one unit of the product, so the profit per unit of production, as is known, represents the difference between the selling price of a unit and its variable cost, and therefore an increase in the selling price of a unit while maintaining a certain level of costs and the volume of activity, increases in Profits. And pricing decisions for commodities are among the most important decisions taken by the management of the facility, so any facility aimed at achieving profit must determine, amend and constantly review the prices that must be loaded for customers and the decision to change the price necessarily affects the number of units sold of the product, as well as sales revenue and profitability The product, and the management often seeks to change the price in the hope of increasing the profitability of the product despite the volume of sales may decrease, as in other cases the price change may be a reaction or response to what competes with the establishment, and setting prices requires studying a market for products The establishment and study the cost of production The product, which is the starting point for setting the price [7]. The accounting method for determining prices depends on the cost plus the target surplus, and we can say that the selling price of the unit is determined according to the following steps:

- Determining the unit's variable costs based on variable cost elements, which include industrial, marketing, and administrative costs.

- Determine the return on contribution per unit by the following formula:

- Contribution revenue $=$ variable cost per unit $\mathrm{x}$ desired contribution rate ratio.

- Determine the selling price by adding the return of the contribution to the variable cost.

After knowing the reason for changing the product and the way to determine it, an important question remains

\section{What is the effect of changing product prices on accounting profits?}

The increase in the sale price per unit with fixed costs and volume of sales will necessarily lead to a decrease in the break-even point, as this increases the return on contribution per unit that in turn led to an increase in the capacity of one dinar of sales to absorb fixed costs, which will lead to an increase in accounting profits. As for the change in decrease concerning the selling price per unit of production with the stability of the aforementioned factors, it works to decrease the return on contribution per unit, which leads to an increase in the break-even point and consequently a decrease or decrease in the number of accounting profits. However, the increase in the unit's selling price may have a greater impact on the scientific reality on the size of the units that the company can sell competitively, and the price effect may lead to a decrease in profits. On the contrary, lowering the price may provide the project with greater profits by compensating the price difference with the additional amount of sales. However, the company's cuts may face similar behavior from competitors, which may lead to a significant decrease in profits, in addition to the possibility of the company's market share decrease. And the establishment, to avoid these events, determines the selling price of the unit in a way that enables it to reach the target profit in the planning stage through the following formula:

Selling price per unit $==$ variable cost per unit + fixed costs + Target profit $/$ expected sales amount

This equation is also used in the case of the establishment's desire to change the price, as it enables it to test the ability of the new price to achieve profits and its effect on sales volume. Finally, if we take the factor of price change for the units produced separately with the factors of the volume of sales and costs fixed, its relationship with the accounting profits is straightforward, so the profits increase with the price increase and decrease with its decrease, but if other factors occur, the relationship becomes based on the rates of change and Market conditions.

\section{Third: Changes in the level of costs (fixed and variable)}

Costs exist in all types of organizations that are for-profit or not-for-profit (service or productive) and the types of costs they incur and the way they are categorized dependent on the types of organizations. There are several foundations for classifying costs, we will rely here on the most common and most closely related to the change in accounting profits, which is the classification of cost elements according to their relationship to the volume of activity and as follows [2].

Fixed costs 
It is the group of elements that are not related to the volume of production as long as the level of activity is within the appropriate range, and therefore it does not change as a group with the change in the volume of activity. Such as the monthly and annual rent of the facility building. And these costs are characterized by the fact that the share of the product from them is inversely proportional to the level of activity. If the activity volume increases, then the share of the product unit of costs will decrease by the same percentage, and it is also characterized by stability in the total.

\section{Variable costs}

They are the elements of costs that change as a group with the change in the volume of activity. Examples include the cost of direct materials, direct work, and direct services. They are distinguished by the fact that the unit cost of each of these elements is fixed. Reduced and non-existent in case of stopping production.

\section{Mixed costs}

They are the elements of costs that consist of a fixed part and another variable and are usually called semi-variable or semi-fixed costs and that is according to the greater part in it and from its characteristics that they do not change completely with changes in the activity size as they change in a rate different from the rate of change in the volume of activity and do not exist The activity stops, and examples include maintenance expenses, and our dependence on the first two groups will be on the understanding that the semi-variable costs are the fixed part of it in the range of fixed costs and the variable part of it is in the range of variable costs, and accordingly we will start studying the effect of fixed costs and variable costs on profits Calculation.

\section{The effect of changing fixed costs on accounting profits}

The reasons for the change in the fixed costs lie with the conditions and policies that the administration faces or takes, such as an increase or decrease in the salaries of employees and an increase or decrease in the number of employees or the rent of the factory area or the expenses of electricity and water or the extinction of equipment, and the change over the successive financial years will be different from a financial period to Others according to the developments and policies pursued by the establishment management, for example, some circumstances and their effects on the operations of the establishment are estimated when preparing financial statements such as depreciation allocations, so sometimes the conditions are not identical to reality, then these estimates must be reconsidered and Disclosure of this in the financial statements [5]. If we assume an increase in fixed costs with a fixed return on the contribution, this will lead to an increase in the break-even point (the point at which the profits are = zero) and then a decrease in accounting profits. As for the decrease in fixed costs, it will make the break-even point decrease with the same percentage, which means that the decrease in fixed costs increases the enterprise's opportunity to achieve profits. As a result, the increase in fixed costs leads to a significant reduction in profits. On the contrary, reducing profits is considered a direct and effective way to improve the profits of the establishment, and this indicates the opposite relationship between them.

\section{The effect of changing variable costs on accounting profits:}

The variable costs are linked as we explained the size of the activity, and change as a group with the change in the level of activity with the fixed share of the unit from them, and the variable costs are a key factor in the changes shown on the accounting profits for the successive financial years, then the increase in the unit cost of sales with the constant price and other factors will lead to An increase in the break-even point, and consequently a decrease in accounting income in that financial period. The reason for this is a decrease in the contribution margin per unit. The increase in the variable cost of the unit should be covered by an increase in the volume of sales [18]. As for the change in decrease concerning the variable costs, it leads to a decrease in the break-even point and consequently an increase in the number of accounting profits due to the high return on contribution per unit. This shows the inverse relationship that links variable costs with accounting income, and if the administration can reduce the variable costs of production, this procedure will affect profits at the current levels of production, working to expand the profit area and at the same time it reduces the chances of a loss occurring [21].

\section{Fourth: The effect of the sales mix on income:}

We explained in the explanation of the previous factors affecting income, the extent of their impact when changed, with an increase or decrease in income, and the relationship between them, in light of the assumption that the enterprise produces and sells only one product. But what would be the effect on the accounting profit of an enterprise dealing with more than one product? The sales mix is the relative union of the number of products or services that constitute the total 
revenue. If the mixture changes, then the planned revenues can continue to be achieved despite the change in the mix ratio, but the effects on operating income depend on how the original proportions of the products shift within the formation up or the lowest which is the contribution margin. As for the reason for changing the accounting income due to the change in the sales mix, it is due to the change in the parity point of the products, as there is not a single number for parity, but rather depends on the mix of revenues, and the change of a percentage of a commodity in the mix will inevitably affect the parity point, and thus a change in the net number of accounting profits will appear. Depending on the change in commodity formation. And the change in profits increases or decreases depending on the type of commodity whose percentage has changed at the expense of another commodity. For example, an increase in the sales of a commodity (A) at the expense of commodity (B) may reduce the parity of products and raise the level of profit, and it may be the opposite.

The product break-even point is calculated by a set of steps [7]:

- Extracting the contribution revenue for each product separately.

- Calculating the contribution rate for each product separately.

- Calculating the revenue from the sales of each product separately, then finding the total value of the sales of the products to reach the value of the sales mix.

- Extracting the ratio of sales revenue of each product to the value of the sales mix.

- Extracting the weighted average of the contribution return ratio, by weighting the contribution return ratio for each product by the percentage of its sales revenue in the sales mix.

- Apply the equation as follows: fixed costs $\backslash$ Weighted average contribution rate ratio

- The plant's break-even point is distributed according to the percentage of sales revenue for each product in the sales mix.

Despite the administration's desire to maximize revenue from all products, it is necessary to adapt to the resources available to the facility to reach the largest proportion of the utilization of production capacity and to know which products should increase its percentage within the available resources [23].

\section{Fifth: Income changes in periods of economic inflation}

Economists of the capitalist world see the economic problem mainly as an imbalance between the available resources and needs, which is what they called economic scarcity, and inflation is only part of this problem, which is represented in the scarcity of resources and a large number of human needs [13]. The concept of economic inflation differs according to the schools and theories that explain it according to its concepts. Some of them see the rate of upward movement in the general level of prices, and some of them see an increase in the general level of prices for goods and services and a decrease in the purchasing power of the monetary unit. And the accounting system based on the entrance of the historical cost suffers a clear deficiency in the periods in which the rates of economic inflation rise, so what led the researchers and the authorities concerned with setting accounting standards to call for the need to amend the accounting data prepared according to the principle of historical cost during periods of high inflation rates to reduce the effects caused by the change in the purchasing power of the currency unit, which is expressed by the term change in the general level of prices [4].

\section{Inflation accounting is based on a set of concepts, perhaps the most important of which are}

\section{The concept of capital preservation}

According to this concept, the entity is supposed to always strive to preserve its economic resources that were in its possession at the beginning of the financial period, if it desires to maintain the continuity of its operating activity and at a level equivalent to at least the operating capacity that was provided to it at the beginning of the period. According to this concept, the result of the establishment's activities is measured by the difference that occurs between the real value of its financial resources at the beginning of the period and the real value of those resources at the end of the period, which requires a measurement between the two values in a unit of cash with a fixed value that eliminates the effects of the fluctuation of the purchasing power of this unit [14]. Accordingly, the preparation of financial statements under the principle of historical cost in light of the assumption that the value of the monetary unit is consistent is inconsistent with the concept of maintaining real capital because the numbers contained in these lists become without meaning or meaning as long as they do not represent fairly as a result of the establishment or its current position. 


\section{The concept of the purchasing power of the monetary unit}

The purchasing power of the monetary unit is represented in a specific time moment for the number of units of a particular commodity that can be purchased with this unit at that moment. For example, if it is possible to purchase five kilograms of rice in one dinar at a particular moment, but due to the inflation factor that occurred during this year, it is not possible to obtain Except for only four kilograms against one dinar, then if we neglect all the factors affecting the price of the commodity except inflation, we can say that the purchasing value of the dinar has become equivalent to only $80 \%$ of its previous purchasing value, meaning that the value of the low purchasing power (or inflation rate) of the dinar Refer 20\% [20]).

\section{As for the treatment of economic inflation, there are several approaches that we summarize as follows}

\section{Accounting the general level of prices}

According to this method, the report or registration on the assets, liabilities, revenues, and expenses is done in monetary units with fixed purchasing power, and this type of method is used to amend historical financial statements while recognizing the variables in the general purchasing power at the general level of prices, the amendment is limited to transferring the cost Historical measured in terms of units of general purchasing power. This approach is characterized by the fact that it meets the requirements of maintaining real capital, but its most important disadvantage is that it neglects the changes in the special levels of prices that occur on the special prices of some assets due to technological developments [25].

\section{Current Cost Accounting}

This method takes into account the change in the prices of each type of financial position, whether by increasing or decreasing. And this entrance surpasses the previous entry in that it is considered a way to maintain real capital and it is characterized by it taking into account the change in the prices of each type of financial position, whether by increasing or decreasing, as for the most important criticism directed against it, it is difficult in many It is often possible to obtain the current cost of an asset due to the lack of published prices of it at all times [26].

\section{Adjusted current cost accounting}

According to this method, accounting for the previous two entries is combined, as it reflects the evaluation of the current cost based on the constant purchasing power. In summary, in a period of economic inflation, the profit figure appears in the statement of income prepared according to the principle of historical cost, amplifying its true value and how to make any distributions paid by it to the shareholders that hit the company's capital in many cases, and that both the values of assets and liabilities that appear In the budget, it is also far from its current value at the date of preparing the budget, which is reflected in the true value of the net assets represented by the shareholders 'rights [24].

Sixth: The effect of the level of current assets on profitability:

Before starting to study the effect of the level of current assets on accounting profits, we must get to know an important concept in this matter, which is the concept of working capital. Capital is defined as the difference between current assets and current liabilities and includes cash circulating assets, debtors, receivables, stocks, securities, and prepaid expenses. Either current liabilities consist of creditors, payment notes, short-term loans, loan installments due during the year and accrued expenses. The size of current assets and current liabilities varies from one facility to another, depending on the size of the facility and the nature of the activity that it is engaged in. And we can clarify the effect of the level of current assets on income through the ratio of current assets to total assets, and this ratio shows us the relative importance of current assets, whether it is an increase or decreases with the assumption of the stability of the rest of the assets during the financial period, the increase in the ratio of current assets to a total Assets lead to a decrease in profitability, and accordingly, the profitability of current assets is less than the profitability of fixed assets, but when this ratio decreases, this will increase profits, and the increase in profits will result from the increase in fixed assets, which is usually more profitable than profitability Assets traded [6]. We can also know the effect of the change in current liabilities on profits by using the same ratio with reliance on current liabilities instead of current assets, in the case of an increase in current liabilities, this will lead to an increase in accounting profits, and if the ratio of current liabilities to the total assets 
decreases, it will lead to an increase Working capital and lower profits as a result of the increase in the cost of conversion. The decrease in current liabilities is due to a decrease in accounting earnings [22].

\section{Seventh: Facility management and the policies followed:}

Facility management has a major role in the conduct of operations and activities that it performs, and consequently, its role and impact on the result of its operations in the financial period grow. The policy pursued by successful management in aligning with the factors influencing mainly the outcome of its final business and its ability to absorb, control and shape it in a manner that ensures maximizing its profits and its continuity in the competitive markets leads to a large extent to its stability, success, and popularity. The department works to support the reasons that lead to profit and avoid the difficult conditions that you may go through. On the sales side, for example, it works to improve the quality of the product and increase the efficiency of workers and create the appropriate conditions to achieve the largest amount of sales to maximize profit, and also works to gain consumer satisfaction and attract them towards the commodity that it produces.

The role of the facility management in changing accounting profits is demonstrated in unit pricing decisions, where determining the appropriate price per unit in sales according to specific requirements and circumstances governs this decision, as well as reducing variable costs while maintaining the quality and efficiency of the product and reducing fixed costs as much as possible will work to Increase the profitability of the facility. The facility management also calculates financial ratios and break-even analyses to reach the reasons that maximize its profits within the limits of the facility's capacity and production capacity by exploiting the maximum of its production capacity without increasing the burdens and expenses on it. Also, achieving a financial balance between the internal sources of financing (the ability of the enterprise to cover its financial needs) and external (the funds obtained from external sources to finance the investments) is of particular importance because it affects the exploitation of the facility on the one hand and the profitability of the facility on the other hand and therefore it works Facility management to achieve this balance [21]. All of this leads us to say that the facility management, although not practically related to accounting profits, such as the correlation of sales, their price, and their cost that is sensitive to the profit, the role of the administration and its association with these profits through its policy and decisions may outweigh every other factor that has an impact on The result of the works of the facility.

\section{PRACTICAL SIDE}

Industrial SMEs represent one of the important tributaries in supporting the national economy, hence the research interest came to know the factors affecting the fluctuation of accounting profits and their impact on the results of the industrial companies 'business and their sustainability in the competing markets. The questionnaire was used to collect data related to research variables, where 45 questionnaires were distributed to respondents in thirty industrial SMEs in Basra, according to three forms for each company, distributed to the general manager, accountant, and auditor in each company, and 40 questionnaires valid for analysis were received. The questionnaire included three axes. The first was to address demographic information on the individuals of the sample. Research, while the second axis includes a set of questions that clarify the relationship between the factors affecting and the fluctuation of accounting profits, while the third axis of the questionnaire included the order of the factors affecting the fluctuation of financial profits, as each respondent was asked to sort the factors in descending order according to their importance from the most influencing to the least. The Lekart five-way scale was used in light of this, the sample can be illustrated as in tables (1), (2), (3) as well as display the research results and test hypotheses.

\section{First: analyzing the characteristics of the research sample}

Table 1: It shows the relative distribution of the study sample individuals according to the educational qualification

\begin{tabular}{|c|c|c|}
\hline Educational qualification & Statistical frequency & The percentage \\
\hline Bachelor's degree & 26 & $65 \%$ \\
\hline Diploma & 14 & $35 \%$ \\
\hline Total & 40 & $100 \%$ \\
\hline
\end{tabular}


We note that $65 \%$ of the individuals in the study sample have a bachelor's degree, while $35 \%$ of the members of the study sample are diploma holders, which reflects the importance of the scientific level for the research sample.

Table 2: It shows the relative distribution of the study sample individuals according to the scientific specialization

\begin{tabular}{|c|c|c|}
\hline scientific specialization & Statistical frequency & The percentage \\
\hline Accounting & 21 & $52.5 \%$ \\
\hline Financial and banking sciences & 11 & $27.5 \%$ \\
\hline Another & 8 & $20 \%$ \\
\hline Total & 40 & $100 \%$ \\
\hline
\end{tabular}

We note that $52.5 \%$ of the individuals in the study sample are accountants, and $27.5 \%$ of those who specialize in financial and banking sciences, while $20 \%$ of other disciplines and this is another indication of the academic qualification, as the specialization in the accounting, financial and banking sciences accounted for $80 \%$ of The size of the sample, as this specialization provided the appropriate floor to ensure a correct answer to the questionnaire for their direct relationship to the accounting field.

Table 3: It shows the relative distribution of the study sample individuals according to the number of years of service

\begin{tabular}{|c|c|c|}
\hline Number of years of experience & Statistical frequency & The percentage \\
\hline 5-9 years & 3 & $7.5 \%$ \\
\hline 10 years and over & 37 & $92.5 \%$ \\
\hline Total & 40 & $100 \%$ \\
\hline
\end{tabular}

We note that $7.5 \%$ of the study sample individuals have years of experience ranging between (7-10 years), while $92.5 \%$ of respondents have experience of 10 years or more, and this is a good indication of the level of accumulation of their experience.

\section{Second: Display the search results}

Descriptive statistics were used to extract the mean and the standard deviation of the study questions. The results are summarized in table (4) below. We note that the directions of the research sample are generally positive towards all study questions because their arithmetic averages are greater than the average of the measuring instrument and the amount (3). I mean, there is great importance for all the variables, as it has the highest percentage (4.12), which is that the change in the size of the assets has an influential role in the fluctuation of profits, while the lowest percentage (3.22) came, which indicates the analysis of financial ratios, a role in reducing the fluctuation of profits, while it was graduated The rest of the circles according to their importance, as for the varied answers about K. Question note that this low contrast and this means the homogeneity of the sample answers to members of the research and not dispersed. Below is table 4 showing the mean and standard deviation of the questions addressed to the study sample:

\begin{tabular}{|l|c|c|c|}
\hline \multicolumn{1}{|c|}{ Factors } & $\mathrm{N}$ & Mean & Std. Deviation \\
\hline F1 Assets Size & 40 & 7.2500 & .83972 \\
F2 Sale Mix & 40 & 6.4250 & .84391 \\
F3 Economic Inflation & 40 & 5.4000 & .84124 \\
F4 Sales Volume & 40 & 4.6000 & .49614 \\
F5 Fixed Assets & 40 & 3.5500 & .50483 \\
F6 Variable Costs & 40 & 2.5500 & .50372 \\
F7 Sale Price & 40 & 2.0500 & .50263
\end{tabular}




\begin{tabular}{c|l|l|l|l|l}
$\begin{array}{c}\text { Table 4: } \\
\text { mean and } \\
\text { deviation }\end{array}$ & $\begin{array}{l}\text { F8 Establishment Policy } \\
\text { Valid N (listwise) }\end{array}$ & $\begin{array}{l}40 \\
40\end{array}$ & 2.0450 & .40577 & $\begin{array}{c}\text { Shows the } \\
\text { standard } \\
\text { of the }\end{array}$ \\
survey questions & &
\end{tabular}

\begin{tabular}{|c|c|c|c|c|}
\hline Questions & $\mathrm{N}$ & Mean & Std. Deviation & Std. Error Mean \\
\hline O1 & 40 & 4.12 & .757 & .120 \\
Q2 & 40 & 4.00 & 1.038 & .164 \\
Q3 & 40 & 3.75 & 1.056 & .167 \\
Q4 & 40 & 3.85 & .921 & .146 \\
Q5 & 40 & 3.58 & .874 & .138 \\
Q6 & 40 & 3.55 & .932 & .147 \\
Q7 & 40 & 3.22 & .891 & .141 \\
Q8 & 40 & 3.52 & .847 & .134 \\
Q9 & 40 & 3.62 & .925 & .146 \\
Q10 & 40 & 3.38 & .838 & .132 \\
Q11 & 40 & 3.32 & .888 & .140 \\
Q12 & 40 & 4.00 & .906 & .143 \\
Q13 & 40 & 4.10 & .496 & .078 \\
\hline
\end{tabular}

Respondents also answered in the third axis of the questionnaire on the question of arranging the factors affecting in descending order according to its importance, as it becomes clear to us that the company's assets and the quality of products and costs play an important role in the fluctuation of profits and that the selling price and the policy of the least influential establishment in light of the change of other factors despite their great importance As we have shown previously, while in the case of other factors, they have the greatest effect on fluctuating profits, as shown in table 5 below:

Table 5: The order of the factors affecting the fluctuation of profits 


\section{Degree of Reliability}

In this context, the (Cronbach Alpha) test was used to measure the validity and reliability of the measuring instrument, where the value of (Alpha) $=78.4 \%$, which is a very good percentage being higher than the rate considered acceptable which is $60 \%$.

\section{Third: hypothesis testing}

The null hypothesis is accepted or rejected according to the rule of decision, which is: The null hypothesis is accepted if the calculated value is less than the tabular value that was extracted from the statistical tables or if the alpha value is greater than the value (0.05) which is the value approved in human studies, and the null hypothesis is rejected if the calculated value is greater than the tabular value, also If the value of alpha is less than the value (0.05).

\section{Main hypothesis test}

The effect of (There is no positive statistically significant relationship between the group of basic factors in the enterprise and the accounting profit fluctuation), as shown in tables 6 and 7.

Table 6: Shows the value of T calculated by SPSS and alpha Sig $(0.00)$

\begin{tabular}{|c|c|c|c|c|c|c|}
\hline & \multicolumn{6}{|c|}{ Test Value $=3$} \\
\hline & \multirow[b]{2}{*}{$\mathrm{t}$} & \multirow[b]{2}{*}{ df } & \multirow[b]{2}{*}{ Sig. (2-tailed) } & \multirow{2}{*}{$\begin{array}{l}\text { Mean } \\
\text { Difference }\end{array}$} & \multicolumn{2}{|c|}{ 95\% Confidence Interval of the Difference } \\
\hline & & & & & Lower & Upper \\
\hline factors & 26.985 & 39 & .000 & 45.02500 & 41.6501 & 48.3999 \\
\hline
\end{tabular}

When comparing the calculated value of $\mathrm{T}$ with the tabular value and the value of alpha as shown in the table below:

Table 7: T-test the main hypothesis results

\begin{tabular}{|c|c|c|c|}
\hline Calculated T & Tabular T & Sig (alpha) & Result of the hypothesis \\
\hline 26.985 & 1.684 & 0.00 & Reject \\
\hline
\end{tabular}

We find the calculated value of $\mathrm{T}$ is greater than the value of the tabular $\mathrm{T}$ and the alpha is less than (0.05), Therefore the null hypothesis is rejected and the alternative hypothesis is accepted and this means that there is a Strong and positive relationship between the main factors group and the accounting profit fluctuation.

\section{CONCLUSIONS}

The change in the size of the assets has an influential role in the fluctuation of profits, and accordingly, most members of the sample agree. The increase in the volume of sales leads to an increase in profits, and accordingly, most sample members agree. The low selling price of the products affects the accounting profits. The high selling prices lead to higher profits, but not all members of the sample agree on it. The change in the level of fixed costs has a clear impact on profits, but not all members of the sample agree on it. The increase in fixed costs leads to lower profits. The increase in the size of the profit leads to higher variable costs, but not all members of the sample agree on it. The increase in the proportions of products within the sales mix leads to higher profits. Economic inflation has a major impact on the decline in accounting profits. The increase in the ratio of current assets to total assets leads to a decrease in profitability. The increase in the ratio of current liabilities to total assets increases the number of profits. Management policy plays an important role in the fluctuation in profits. The analysis of financial ratios plays a role in reducing the fluctuation of profits, but it is not agreed upon by all members of the sample.

\section{References}


[1]. Taruté and R. Gatautis, "ICT impact on SMEs performance", Procedia - Social and Behavioral Sciences, vol. 110, pp. 1218-1225, 2014.

[2]. S. Alam and MK. Mohammad Noor, "ICT adoption in small and medium enterprises: an empirical evidence of service sectors in Malaysia", International Journal of Business and Management, vol. 4, no. 2, pp. 112-125, 2009.

[3]. Lopez-Nicolas and P. Soto-Acosta, "Analyzing ICT adoption and use effects on knowledge creation: An empirical investigation in SMEs", International Journal of Information Management, vol. 30, pp. 521-528, 2010.

[4]. F. Saf'ara et al., "Information Technology Incubators: dimention and challenges", 9th annual conference of Iranian computer society, 2003.

[5]. F. Zafar, R. Ishaque and M. Javaid, "Use Of Ict And E-Commerce Towards Achieving Competitive Advantages", European Journal of Research and Reflection in Management Sciences, vol. 2, no. 1, 2014.

[6]. M. Porter, "Strategy and the Internet", Harvard Business Review, pp. 62-78, 2001.

[7]. Y. Bakos, "The Emerging Role of Electronic Marketplaces on the Internet", Communications of the ACM, vol. 41, no. 8, pp. 35-42, 1998.

[8]. N. Manochehri, R. Al-Esmail and R. Ashrafi, "Examining the impact of information an communication technologies (ICT) on enterprise practices preliminary perspective from Qatar", The Electronic Journal on Information Systems in Developing Countries (EJISDC), vol. 51, no. 3, pp. 1-16, 2012.

[9]. P. Matthews, "ICT assismilation and SME expansion", Journal of International Development, vol. 19, pp. 817-827, 2007.

[10]. Q. Pham, "measuring the ict maturity of smes", Journal of Knowledge management Practice, vol. 11, no. 1, 2010.

[11]. Consoli, "Literature analysis on determinant factors and the impact of ICT in SMEs", Procedia Social and Behavioral Sciences, vol. 62, pp. 93-97, 2012.

[12]. S. Kim and H. Lee, "the impact of organizational context and information technology on employee knowledge-sharing capabilities", public administration review, vol. 66, no. 3, pp. 370-385, 2006.

[13]. F. Matambalya and S. Wolf, "The Role of ICT for the Performance of SMEs in East Africa - Empirical Evidence from Kenya and Tanzania", ZEF - Discussion Papers on Development Policy, vol. 4, no. 2, 2001.

[14]. Brynjolfsson and L. Hitt, "Information technology as a factor of production: The Role of Differences Among Firms", Economics of Innovation and New Technology, vol. 3, no. 4, pp. 183-200, 1995.

[15]. Brynjolfsson and L. Hitt, "Computing Productivity: Firm Level Efficiency", 2000.

[16]. Jian Wu. "The establishment and application of commercial banks internal rating system". Modern commercial bank journals. September 2002.

[17]. Zhenyu Li, Xinhong Li, Liqiang Shao. "Credit rating principle", Peking, China's founder press, 2003.

[18]. Di Ai, DeKai. "The bank's risk management", China's financial press, May 12004.

[19]. Xinjiang Wei "Financial regulatory", China's financial press, February 1, 2005.

[20]. Ingmin Yanq, "China banking risk assessment and early warning system research", China's financial press, March 1, 2005.

[21]. T. S. Baines, H. W. Lightfoot and O. Benedettini, "The servitization of manufacturing: A review of literature and reflection on future challenges", J. Manuf. Technol. Manage., vol. 20, pp. 547-567, 2009.

[22]. J. Gao, Y. Yao, V. C. Y. Zhu, L. Sun and L. Lin, "Service-oriented manufacturing: A new product pattern and manufacturing paradigm", J. Intell. Manuf., vol. 22, no. 3, pp. 435-446, Jun. 2011.

[23]. T. S. Baines, H. W. Lightfoot, S. Evans, A. Neely, R. Greenough, J. Peppard, et al., "State-of-the-art in product-service systems", Proc. Inst. Mech. Eng. B J. Eng. Manuf., vol. 221, no. 10, pp. 1543-1552, Oct. 2007.

[24]. Q. Q. Zhu, P. Y. Jiang, G. Q. Huang and T. Qu, "Implementing an industrial product-service system for CNC machine tool", Int. J. Adv. Manuf. Technol., vol. 52, no. 9, pp. 1133-1147, Feb. 2011.

[25]. P. Sun, C. Zhang, P. Jiang and W. Cao, "Cutting-tool delivery method in the context of industrial product service systems", Concurrent Eng., vol. 24, no. 2, pp. 178-190, Jan. 2016.

[26]. W. Zhang, J. Guo, F. Gu and X. Gu, "Coupling life cycle assessment and life cycle costing as an evaluation tool for developing product service system of high energy-consuming equipment", J. Cleaner Prod., vol. 183, pp. 1043-1053, May 2018. 